\title{
The evolution characteristics of rainstorm in major large cities of China
}

\author{
Yingdong $\mathrm{Yu}^{1,2, \mathrm{a}}$, Jiahong Liu ${ }^{1,2, \mathrm{~b}}$, Zhiyong Yang ${ }^{1.2, \mathrm{c}}$ and Sheng Yan ${ }^{1.2}$ \\ ${ }^{1}$ State Key Laboratory of Simulation and Regulation of Water Cycle in River Basin, \\ Beijing 100038, China; \\ ${ }^{2}$ China Institute of Water Resources and Hydropower Research, Beijing 100038, China. \\ ayuyingd@iwhr.com, bliujh@iwhr.com, cyangzy@iwhr.com
}

Keywords: rainfall characteristics, rainstorm, large cities, China.

\begin{abstract}
Under the background of climate change and human activities, the rainfall characteristics has changed seriously in recent years around China. The main characteristics of rainstorm has also significant change in most large cities. The frequency, intensity and duration of rainstorm varied in many different cities. The urbanization effect play an important role in the diverse of rainstorm in cities. In this study, 44 cities around 36 cities are selected for analyzing the inter-annual change of rainstorm characteristics. The results show that the rainstorm frequency and intensity of rainstorm increase in most parts of China. The change of accumulated rainfall and rainstorm duration differs varies from city to city.
\end{abstract}

\section{Introduction}

As an urban extreme climate event, urban rainstorm has a serious impact on urban security. Urban climate characteristics are affected by the background of regional climate. At the same time, the human activities in the process of urbanization also play an important role in the change of urban extreme precipitation. In recent years, the frequency of short duration and high intensity precipitation is rising in most cities of China. The rainstorm has a huge impact on society which often causes disaster in China's cities. Therefore, the temporal and spatial distribution characteristics of urban rainstorm need to be urgently launched.

Many experts have done much work on the rainstorm or extreme precipitation in cities. Gabriëlle [1] analyze the characteristics of rainstorm over Belgium based on weather radar images. Ghazi [2] investigated the characteristics of rainstorm temporal distribution in Oman. The results show that there was a minor difference in rainstorm temporal distribution between arid mountains and Costal regions. Monica [3] has identify regions of extreme precipitation in mainland Portugal and create a single index of extreme precipitation susceptibility. Elena [4] analyze the extreme precipitation over the Crimean peninsula. The results show that the number of extreme precipitation days in the winter season is up to $30 \%$ higher in the negative PDO phase over the whole territory of Crimea, while in the summer it is up to $60 \%$ lower in the south-eastern part of peninsula. Dörte[5] apply a consistent methodology to examine the lonngterm change of extreme precipitation in Australia. It indicates that daily precipitation extremes rarely exhibit long-term change over the century but are strongly modulated by the El Niño Southern Oscillation (ENSO). Some experts also analyze the change of extreme precipitation in China. Xiaoli Wang [6] investigate the spatiotemporal variations of extreme precipitation events in the Costal area of China. Results revealed that there was a generally insignificant upward and downward tendency of extreme precipitation events in the southern and northern coastal area, respectively. Xihui Gu[7] examines the seasonality and nonstationarity in the timing of extreme precipitation using circular statistics. The average seasonality is subject mainly to summer season (June-July - August), which is potentially related to East Asian monsoon and Indian monsoon activities. Ren Zhengguo[8] analyze the extreme precipitation in South China during 1961-2011. The results shows that the average of precipitation indices shows a significant spatial difference with drier northwest section and wetter southeast section. Some experts have researched the evolution law of rainstorm and extreme precipitation in other regions of China [9-11]. 
Although many researchers have analyze the characteristics of rainstorm or extreme precipitation in some regions of China. The investigation of urban rainstorm is few. It is urgently needed for analyzing the characteristics of extreme precipitation in major cities. In this study, 36 cities are selected for investigating the change of rainstorm.

\section{Methods}

\subsection{Study area}

The precipitation data used in this study are derived from hourly precipitation data from 2480 meteorological stations in China during the period 1961 2010. Based on the total meteorological stations, 44 stations covering 36 cities (31cities lie in the country from the capital city and other sub provincial city) are selected in this research. The observation data of 52 stations are used as the data base. The Dem elevation map of China can be seen in Figure1.

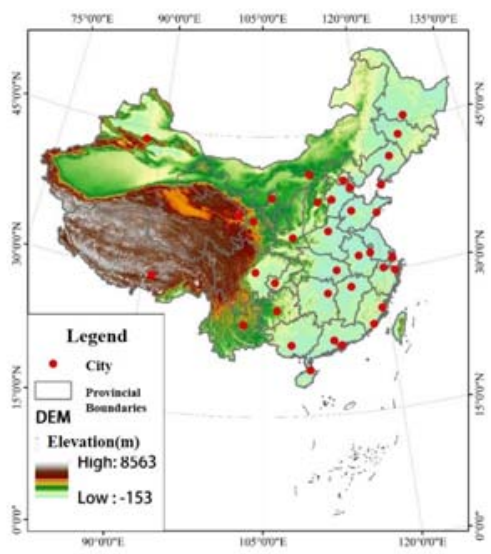

\subsection{Methods}

Fig. 1 China DEM elevation map

In this study, the rainstorm is regarded as daily extreme high precipitation. Considering the total amount of precipitation in 24 hours or 12 hours. Based on the above meteorological data, using FORTRAN programming tools, the rainstorm frequency, rainstorm duration and rainstorm intensity are caculated respectivly during 1961-2010. The definition of rainstorm is listed in Table 1 . If the continuous precipitation accumulation is greater than $5 \mathrm{~mm}$, it is considered as a rainfall process.

Table 1. The definition of rainfall and rainstorm

\begin{tabular}{|c|c|c|}
\hline & Time ( hours) & Accumulated Rainfall(mm) \\
\hline Rainfall Process & $/$ & $>5$ \\
\hline \multirow{2}{*}{ Rainstorm Process } & 12 & $>30$ \\
\cline { 2 - 3 } & 24 & $>50$ \\
\hline
\end{tabular}

The trend analysis approach is applied for analyzing the change of rainstorm frequency, intensity and duration. The Cluster analysis method is used for classify the rainstorm in different cities. According to the characteristics of rainstorm change, the rainstorm is classified into different types.

\section{Rainstorm characteristics in major cities}

According to the administrative divisions of our country, the 44 cities are divided into 7 regions to evaluate the change of rainstorm characteristics. The 7 region include East China, South China, North China, Northeast China, Northwest China, Central China and Southwest China. The investigation of rainstorm characteristics in 7 regions are shown below respectively.

\subsection{East China}

In this study, 13 stations are selected for investigating the change of rainstorm characteristics in East China. Selecting the most representative Longhua station to show the evolution role of rainstorm in this region. The overall performance is high frequency and short duration rainfall process is 
increasing year by year. In addition, the average annual rainstorm frequency of Longhua Station is $6.13 \%$, and the annual average values of rainstorm accumulated rainfall, rainstorm duration and rainstorm intensity are $60.91 \mathrm{~mm}, 14.52 \mathrm{~h}$ and $6.51 \mathrm{~mm} / \mathrm{h}$ respectively. The characteristics of rainstorm, cumulative rainfall, rainfall intensity duration can be seen in Figure 2.

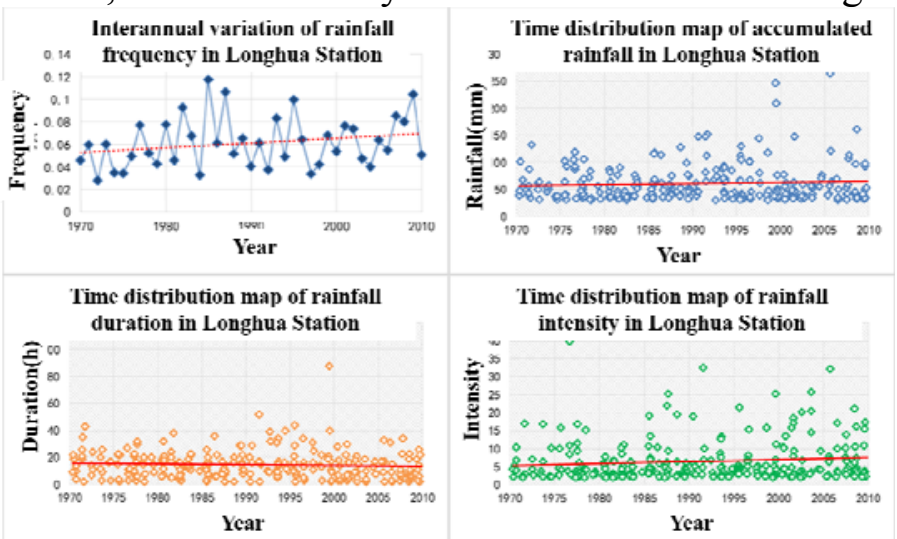

Fig.2 Distribution map of rainstorm frequency, cumulative rainfall, rainfall intensity and rainfall duration in LongHua station

\subsection{South China}

Four stations are picked for analyzing the change of rainstorm characteristics in South China. Selecting the most representative Guangzhou station to illustrate the evolution role of rainstorm in this region. The results show that the frequency and intensity present an increasing trend. The accumulated rainfall and rainstorm duration had no obvious change. In addition, the average annual rainstorm frequency of Guangzhou Station is $7.82 \%$. The annual average values of rainstorm accumulated rainfall, rainstorm duration and rainstorm intensity are $61.64 \mathrm{~mm}, 11.85 \mathrm{~h}$ and $7.07 \mathrm{~mm} / \mathrm{h}$ respectively. The change of rainstorm characteristics can be seen in Figure 3.

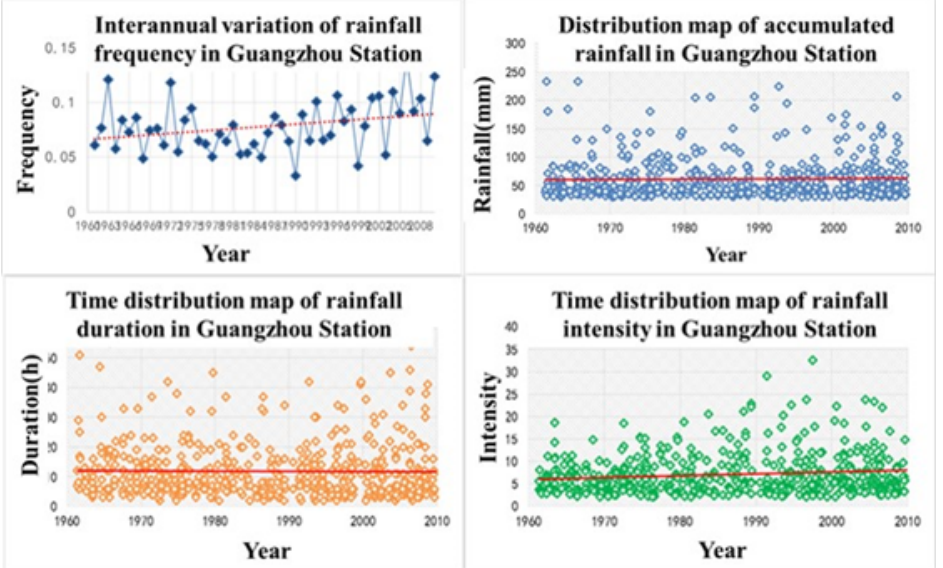

Fig.3 Distribution map of rainstorm frequency, cumulative rainfall, rainfall intensity and rainfall duration in Guangzhou Station

\subsection{North China}

In North China, eight stations are chosen for analyzing the rainstorm characteristics. Choosing the most typical Haidian station to investigat the change of rainstorm in this region. The results indicate that the frequency and intensity present an increasing trend. The accumulated rainfall and rainstorm duration show a downward trend. Furthermore, the average annual rainstorm frequency of Haidian Station is $5.93 \%$. The annual average values of rainstorm accumulated rainfall, rainstorm duration and rainstorm intensity are $55.43 \mathrm{~mm}, 11.24 \mathrm{~h}$ and $7.07 \mathrm{~mm} / \mathrm{h}$ respectively. The change of rainstorm characteristics can be seen in Figure 4. 

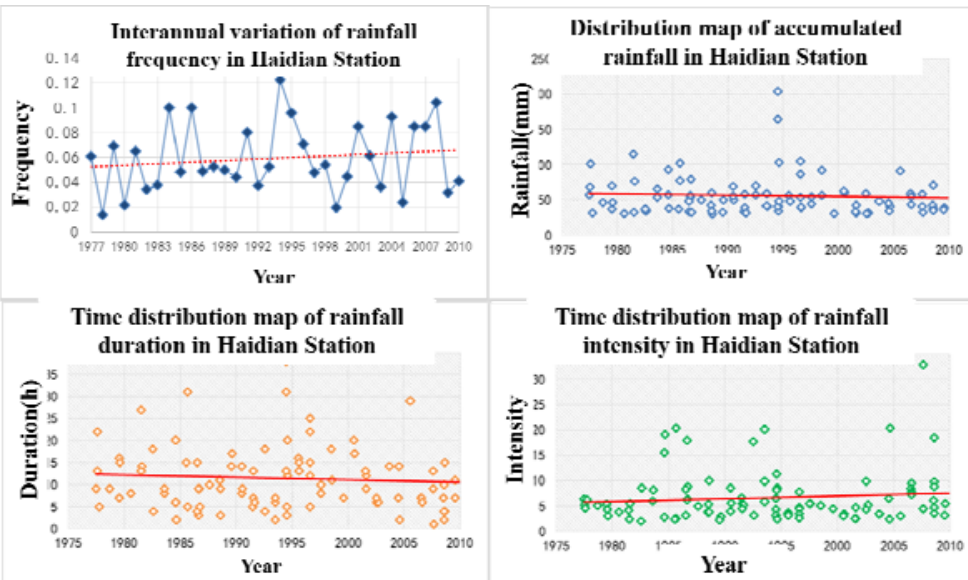

Fig.4 Distribution map of rainstorm frequency, cumulative rainfall, rainfall intensity and rainfall duration in Haidian Station

\subsection{Northeast China}

Northeast China include Heilongjiang Province, Liaoning Province, Jilin Province and prat of Inner Mongolia. Four stations are selected for analyzing the rainstorm change in this study. Selecting the most repsentative Haerbin station to analyze the change of rainstorm.Results show that the frequency and intensity of rainstorm present an increasing trend. The accumulated rainfall and rainstorm duration did not change seriously. In addition, the average annual rainstorm frequency of Haerbin Station is 3.54\%, and the annual average values of rainstorm accumulated rainfall, rainstorm duration and rainstorm intensity are $49.58 \mathrm{~mm}, 10.75 \mathrm{~h}$ and $6.91 \mathrm{~mm} / \mathrm{h}$ respectively. The main character of rainstorm, cumulative rainfall, rainfall intensity duration can be seen in Figure 5.
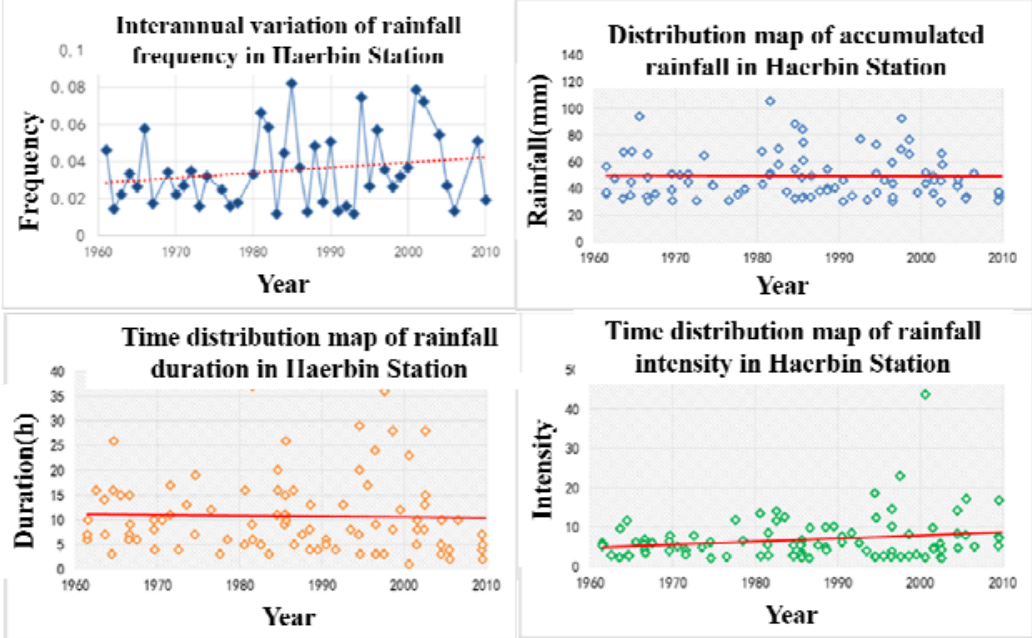

Fig.5 Distribution map of rainstorm frequency, cumulative rainfall, rainfall intensity and rainfall

\subsection{Northwest China} duration in Haerbin Station

Northwest China accounts for about $30 \%$ of the country's total area. In this study, eight stations are chosen for illustrating the rainstorm characteristics. Choosing the most typical Xi An station to investigat the change of rainstorm in this region. The results indicate that all the factors include the frequency, intensity, accumulated rainfall and rainstorm duration present an increasing trend. Moreover, the average annual rainstorm frequency of $\mathrm{Xi}$ an Station is 3.04\%, and the annual average values of rainstorm accumulated rainfall, rainstorm duration and rainstorm intensity are $50.42 \mathrm{~mm}$, $15.25 \mathrm{~h}$ and $4.86 \mathrm{~mm} / \mathrm{h}$ respectively. The main character of rainstorm, cumulative rainfall, rainfall intensity duration can be seen in Figure 6. 


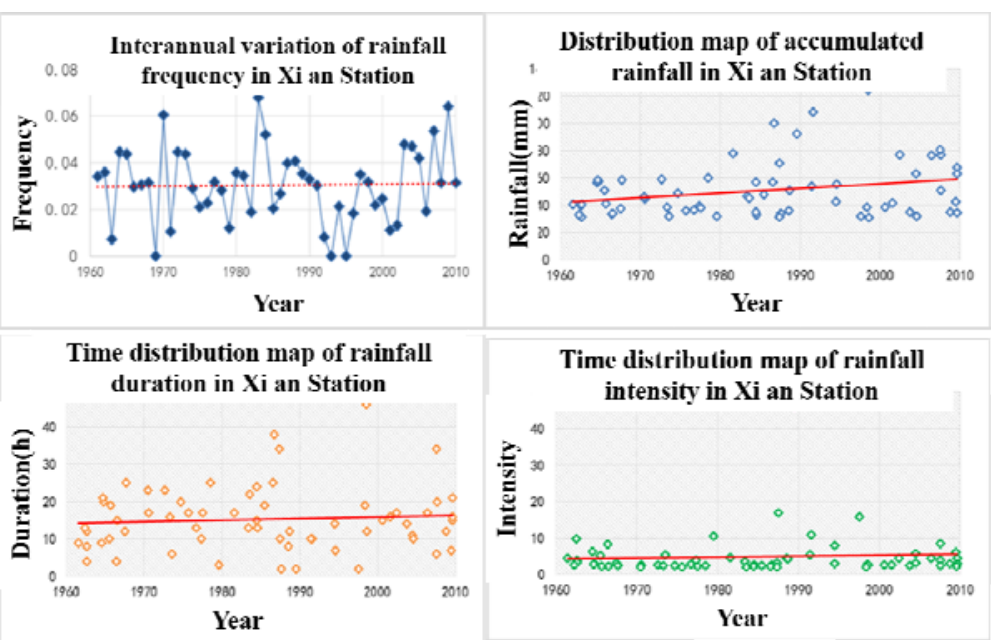

Fig.6 Distribution map of rainstorm frequency, cumulative rainfall, rainfall intensity and rainfall duration in Xi An Station

\subsection{Central China}

Central China includes six neighboring provinces. Wuhan, Changsha and Zhengzhou are selected for analyzing the rainstorm change in this study. Selecting the most repsentative Wuhan station to investigate the feature of rainstorm. Results show that the frequency and intensity of rainstorm present an increasing trend. The accumulated rainfall and rainstorm duration did not change obviously. Furthermore, the average annual rainstorm frequency of Wuhan Station is $8.27 \%$, and the annual average values of rainstorm accumulated rainfall, rainstorm duration and rainstorm intensity are $66.94 \mathrm{~mm}, 15.31 \mathrm{~h}$ and $5.57 \mathrm{~mm} / \mathrm{h}$ respectively. The main feature of rainstorm, cumulative rainfall, rainfall intensity duration can be seen in Figure 7.
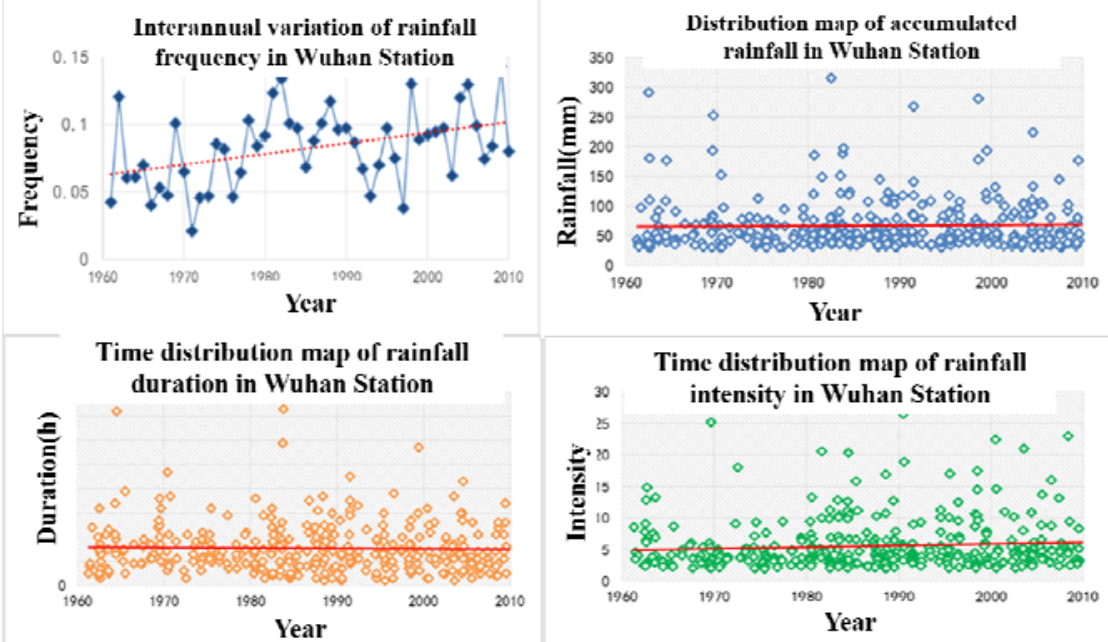

Fig.7 Distribution map of rainstorm frequency, cumulative rainfall, rainfall intensity and rainfall duration in Wuhan Station

\subsection{Southwest China}

Southwest China include five Provinces. In this study, six stations are chosen for detecting the rainstorm characteristics. Choosing the most typical Shuangliu station to investigat the interannual variation of rainstorm in this region. The results show that the frequency and intensity present an increasing trend. The rainstorm duration present an decreasing tendency. The accumulated rainfall had no obvious change. Moreover, the average annual rainstorm frequency of Shuangliu Station is $4.06 \%$, and the annual average values of rainstorm accumulated rainfall, rainstorm duration and rainstorm intensity are $54.06 \mathrm{~mm}, 11.45 \mathrm{~h}$ and $6.11 \mathrm{~mm} / \mathrm{h}$ respectively. The main characteristics of rainstorm, cumulative rainfall, rainfall intensity duration can be seen in Figure 8. 


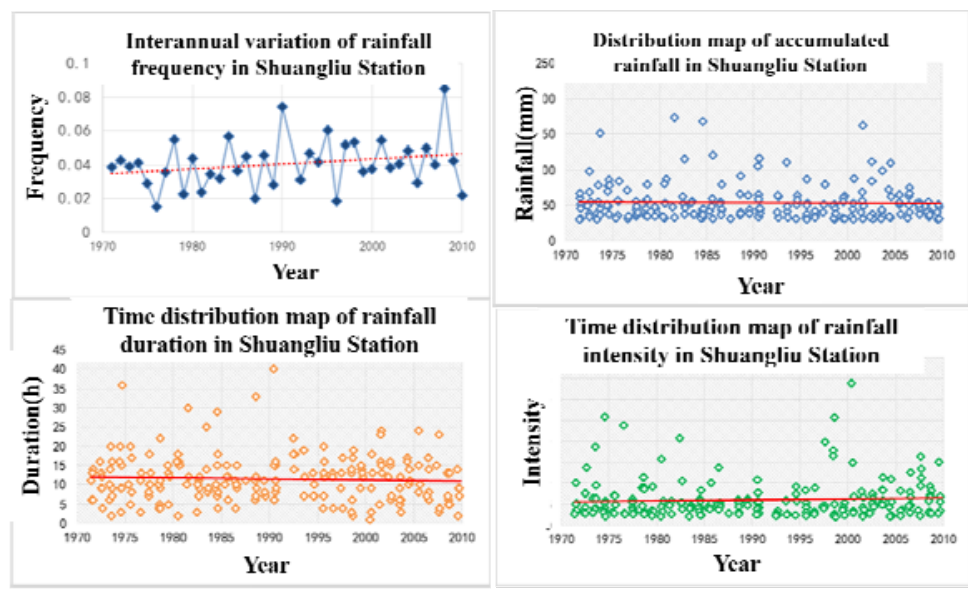

Fig. 8 Distribution map of rainstorm frequency, cumulative rainfall, rainfall intensity in Shuangliu Station

\section{Conclusion}

The first purpose of this study was to analyze the evolution role of rainstorm in major cities of China. For this purpose, 44 stations in 36 cities are selected for indicating the change of rainstorm. The research results can be summed up as follows:

The overall trend of rainstorm characteristic accords with the national precipitation distribution characteristics in most typical cities of China. The total amount of precipitation decreases gradually from southeast to northwest. The rainstorm characteristic grade in cities is higher than or equal to the suburbs.

The frequency and intensity of rainstorm presents an increasing trend in most cities of China. The total amount of accumulated rainfall and rainstorm duration differs from city to city.

The rainstorm evolution has no unified rules in China. It indicates that the effects of climate change in the rainstorm process did not account for the dominant position. The rainstorm evolution may be the comprehensive results of underlying surface, the terrain of local area and the climate effect.

\section{References}

[1]. Gabriëlle J, Niko E, et al. Characteristics of rainstorms over a temperate region derived from multiple time series of weather radar images. Journal of Hydrology. Vol. 307, Issue 1-4, (2005), p. 126-144.

[2]. Ghazi AliAl-Rawas, CaterinaValeo. Characteristics of rainstorm temporal distributions in arid mountainous and coastal regions. Journal of Hydrology. Vol. 376, Issue 1-2, (2009), p. 318-326.

[3]. Mónica Santos, Marcelo Fragoso, João A.Santos. Regionalization and susceptibility assessment to daily precipitation extremes in mainland Portugal. Applied Geography. Vol. 86 (2017), p. 128-138.

[4]. Elena Voskresenskaya, Elena Vyshkvarkova. Extreme precipitation over the Crimean peninsula. Quaternary International. Vol. 409(2016) Part A, p. 75-80.

[5]. Dörte Jakob, David Walland. Variability and long-term change in Australian temperature and precipitation extremes. Weather and Climate Extremes. Vol. 14(2016), p. 36-55.

[6]. Xiaoli Wang, Xiyong Hou,et al. Spatiotemporal variations and regional differences of extreme precipitation events in the Coastal area of China from 1961 to 2014. Atmospheric Research. Vol. 197(2017), p. 94-104.

[7]. Xihui Gu, Qiang Zhang, Vijay P.Singh, PeijunShi. Nonstationarity in timing of extreme precipitation across China and impact of tropical cyclones. Global and Planetary Change. Vol. 149(2017), p. 153-165. 
[8]. REN Zhengguo, ZHANG Mingjun, WANG Shengjie, et al. Changes in precipitation extremes in South China during 1961-2011. Acta Geographic Sinica. Vol. 69 (2014) No.5, p.640-649.

[9]. Analysis on a Regional Heavy Rainstorm Process in North Henan [J]. Meteorological and Environmental Research, 2011, 10:12-16.

[10]. Sensitivity experiments of impacts of large-scale urbanization in East China on East Asian winter monsoon [J]. Chinese Science Bulletin, 2013, 07:809-815.

[11]. Diagnostic analysis of mesoscale rainstorms in the Jiang-Huai valley of China with convective vorticity vector [J]. Progress in Natural Science, 2007, 05:559-568. 